of key individuals and institutions who might otherwise be talking to each other through a megaphone. The group included Tewolde Egziabher, head of Ethiopia's Environmental Protection Authority, who is a leading environmental campaigner and a vocal critic of multinationals in developing countries. Sat next to him was Calestous Juma, a professor of international development at Harvard University and a passionate proponent of technology's role in economic development. And next to him was Cheick Modibo Diarra, chairman of Microsoft in Africa.

The group eventually came to a consensus that Africa's nations cannot afford to do without new technologies in agriculture - but that all new technologies would need appropriate safeguards to protect human health and the environment. This seemingly obvious statement was, in fact, a rare example of successful collaboration between multinationals and environmentalists.

The fragility of that consensus is illustrated by the fate of a much larger initiative, the International Assessment of Agricultural Knowledge, Science and Technology for Development. That effort attempted to forge a similar consensus among the major players in world agriculture, but fell apart in January when industry representatives chose to walk away from the table (see Nature 451, 223-224; 2008). They felt unable to sign a document that did not list biotechnology as a high enough priority.

From the other side, meanwhile, GM opponents are trying to rekindle the controversy. A new opposition campaign www.bangmfood.org - was endorsed in the November issue of The Ecologist magazine, an influential voice in the global environmental movement.

In that context, the magnitude of the African Union panel's achievement is clear - as are the challenges it still faces. Its report, Freedom to Innovate: Biotechnology in Africa's Development, has not yet officially seen the light of day, even though it was published more than a year ago. Ordinarily, a document from the African Union would be expected to be harsh in its criticism of multinational industry. As this report is more measured, senior officials in the African Union's Commission based in
"Africa's nations cannot afford to do without new technologies in agriculture." Addis Ababa are nervous about releasing it.

Happily, the report is in wide circulation and freely available on the Internet (www.nepadst.org/doclibrary/pdfs/biotech_ africarep_2007.pdf). But the African Union should have the courage of its convictions and give the report its formal endorsement. Indeed, it should use it as a model for ongoing attempts to address the food crisis. Both the successful negotiations of the African Union panel and the failure of the international assessment show that there is no alternative to a grown-up discussion with all parties in the same room.

\section{Friendly rivalry}

The spirit of collaboration in the race to define the LHC's successor sets an example for large projects.

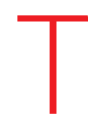
he future for high-energy physics is decidedly mixed. On the one hand, physicists are eagerly awaiting the insights into the Universe promised by the Large Hadron Collider (LHC) at CERN, the European particle-physics laboratory near Geneva. But as governments shift their priorities to societal problems, such as climate change, energy, health and the environment, the field as a whole must also face up to the fact that it will be increasingly difficult to secure funds for pure science.

Given this financial uncertainty, it is important that the highenergy physics community does all it can to reduce any internal divisions and to strengthen its external coherence. That is why a new collaboration over what should come after the LHC is to be greeted with enthusiasm. As a new world-class accelerator requires a decade or more of technology development and coalition-building, physicists are already laying their plans. But until the LHC starts providing data, there will be uncertainty over the energy levels at which its successor should operate. So two competing concepts, backed by rival efforts, have been put forward.

On one side is the International Linear Collider (ILC), which would use electron-positron collisions to pick up where the proton-proton collisions of the LHC leave off (see Nature 451, 108; 2008). The ILC planners are setting their sights on comparatively low energies about 500 gigaelectronvolts per beam - a goal that could be achieved fairly easily with technology that is now maturing. The United States, seeking a return to pre-eminence at the high-energy frontier, has been a driving political force for hosting the ILC. On the other side is the Compact Linear Collider (CLIC) being pushed by CERN. This could conceivably run at energies as high as 3 teraelectonvolts - but the technology to achieve that lies much farther in the future.

The potential for destructive rivalry was real. Yet late last month, leaders of the two efforts formally agreed to collaborate as much as is practicable. Seven joint working groups have been established, covering common efforts ranging from detectors to beam-delivery systems. In a first, the working groups presented joint talks at CLIC and ILC workshops during the past few weeks. One group is trying to put costs and schedules into common terms so that decision makers will find it easier to compare the two when it comes to choosing between the technologies. Another group will save money by applying a CLIC simulation to an ILC design for an accelerator component known as a damping ring. The two rivals are closer than they have ever been, and yet research and development on the two underlying accelerator technologies will continue apace with a healthy spirit of competition.

The rapprochement was not entirely brought about by the current financial crisis - Barry Barish, director of the ILC global design effort, says that talks began well before December 2007, when the US Congress passed a budget that derailed much of the US ILC effort. But the global economic meltdown has certainly made cooperation imperative - not least because it has pushed the next big accelerator even farther into the future. The result is that the ILC and CLIC are setting an example that other large scientific endeavours would do well to emulate. 